\title{
WorldCat Local Implementation: The Impact on Interlibrary Loan
}

Deardorff T., and Nance H. 2009. "WorldCat local implementation: The impact on interlibrary loan". Interlending and Document Supply. 37 (4): 177-180.

\section{Author Information}

Heidi Nance is the Summit and ILL Borrowing Supervisor at the University of Washington Libraries. Heidi received her Master's of Library and Information Science from the University of Washington. Contact information: Heidi Nance, University of Washington Libraries, Box 352900, Seattle, WA 98195, USA, hnance@u.washington.edu

Thomas Deardorff is the Coordinator for Access Services for the University of Washington Libraries. Thomas received his Master's of Library Science from the University of Illinois. Contact information: Thomas Deardorff, University of Washington Libraries, Box 352900. Seattle. WA 98195, USA, tdeardor@u.washington.edu

\section{Introduction}

Founded in 1861, the University of Washington (UW), located in Seattle, Washington, USA, is one of the oldest state-supported institutions of higher education on the western coast of the United States. Composed of more than 47,000 students and 4,100 full time faculty members spread across three campuses, the University offers over 250 degrees within 150 departments across 18 colleges and schools. In addition the University operates and manages two major medical centers: UW Medical Center and Harborview Medical Center.

Such a large research institution is powered by a large research library: the University of Washington Libraries owns 7.14 million volumes and over 61,000 serial subscriptions. UW Libraries is also a member of the local Orbis Cascade Alliance, a local consortium of 36 academic libraries at universities, colleges, and community colleges in Oregon and Washington State. Alliance membership allows the UW to borrow freely from other Alliance libraries' collections using the catalog provided by the Alliance called Summit. Material not held by the UW or Summit libraries can be obtained through Interlibrary Loan.

The UW has three interlibrary loan departments; for the purposes of this paper we will be discussing WorldCat Local's effect on the Main Interlibrary Loan's Borrowing operations, which serves all departments except for Law and Health Sciences (served by their own interlibrary loan operations.)

\section{Interlibrary Loan before the Implementation of WorldCat Local}

The Main Interlibrary Loan office serves undergraduate students, graduate students, and faculty, in the humanities, social sciences, engineering, natural sciences and other non-health related 
fields. Since 1998 ILL borrowing activity had held fairly steady until the introduction of World Cat Local. In the last year before WorldCat Local implementation, 2006-2007, ILL filled 12,039 requests. These requests were filled from 641 individual libraries/article vendors; $91 \%$ of these lenders were in the United States. $63 \%$ of items requested were photocopies of articles and $37 \%$ were for loans of books or other returnable materials such as microform, microfilm, DVDs, CDs, maps, etc. ILL Borrowing employed 2.0 FTE of staff, and 1.26 FTE of student hourly assistance. Staff did the majority of searching, requesting, trouble-shooting, and administrative duties such as bill-paying and reporting. Student employees assisted with processing incoming materials and returning loans to owning institutions.

\section{WorldCat Local Overview}

As the name implies, WorldCat Local (WCL) is a localized version of Worldcat.org, the union catalog of 100 million+ records developed by OCLC, that provides a hierarchy of content based on accessibility. Material held locally at the University of Washington Libraries is shown first, then the content of our regional consortia and then other WorldCat libraries. In addition the content of five article databases are searched : PubMed, ERIC, GPO, ArticleFirst and British Library Serials - providing access to 50,000,000 article citations. WorldCat Local integrates the descriptive information provided from these catalogs and databases with local delivery options including local paging, consortial requests, ILL requests and direct links to online article content using OpenURL.

Prior to the implementation of WCL library, users had to perform multiple searches to locate relevant content: the local University of Washington catalog, the regional consortia catalog, and WorldCat. Direct requesting of material was provided in the local and Summit catalogs but users had to find and complete ILL requesting forms to request content not owned locally or in the consortia. Each resource was in effect an isolated "silo" of information that was not interconnected or easy for users to understand and navigate. Most users would begin and end with the local catalog, a smaller number would use the consortial catalog and only a few hardy souls would seek out and use ILL. All of the article citation databases were separate from the library catalog and required separate searches with separate paths to fulfillment.

\section{Impact on ILL of WorldCat Local Implementation}

When WCL was implemented ILL became fully integrated into the access process. If monographic material was not available either online, in the local catalog or in the consortial catalog the user was presented with a request button that links to our ILLiad system - once a person logs into their ILLiad account the appropriate form would be automatically populated using the OpenURL data generated by WCL. Article requesting was treated in a similar manner with the user seeing a "Check electronic resources" button. If no electronic content was available a link to ILL was provided that would automatically populate an article request form. For articles WCL sends OpenURL data to our link resolver (WebBridge) which then queries our 
electronic serial package data (Serials Solutions). If no online content is found links are provided to the local catalog to search for local print only copies and to ILL. For this process to work successfully holdings in OCLC must be current and a link-resolver and a knowledge database of serial package content must be available to provide information needed to make the correct decision that no local, regional or online content is available and that the user needs to use ILL.

In 2007-2008, following the implementation of WorldCat Local, ILL saw large shifts in the volume and type of requests as well as shifts in the demographics of ILL patrons. We acquired 23,053 items (returnables and non-returnables), a 92\% increase in borrowing over the previous year. Requests for returnable materials: books, media, microfilm/form, etc. were up $150 \%$ and requests for non-returnables, mostly article copies, were up $41 \%$ in the first year. This is consistent with what we would expect as WCL initially provided access to mostly monographic content, much of which was not held locally in print or electronically. Requesting for articles did increase substantially but was mitigated by the large current holdings and backfiles of online article content that was accessible locally. These requests were filled from 970 individual libraries or article vendors - a 51\% increase in lending libraries. The percentage of international libraries held pretty steady - at 7\% - which is interesting because international borrowing of returnables tripled in size, prompting us to revisit and refine our international borrowing procedures for searching, requesting, paying for, and returning internationally held items. The ratio of articles to loans requested abruptly reversed an eight-year trend to become $40 \%$ copies to $60 \%$ loans.

Figure 1

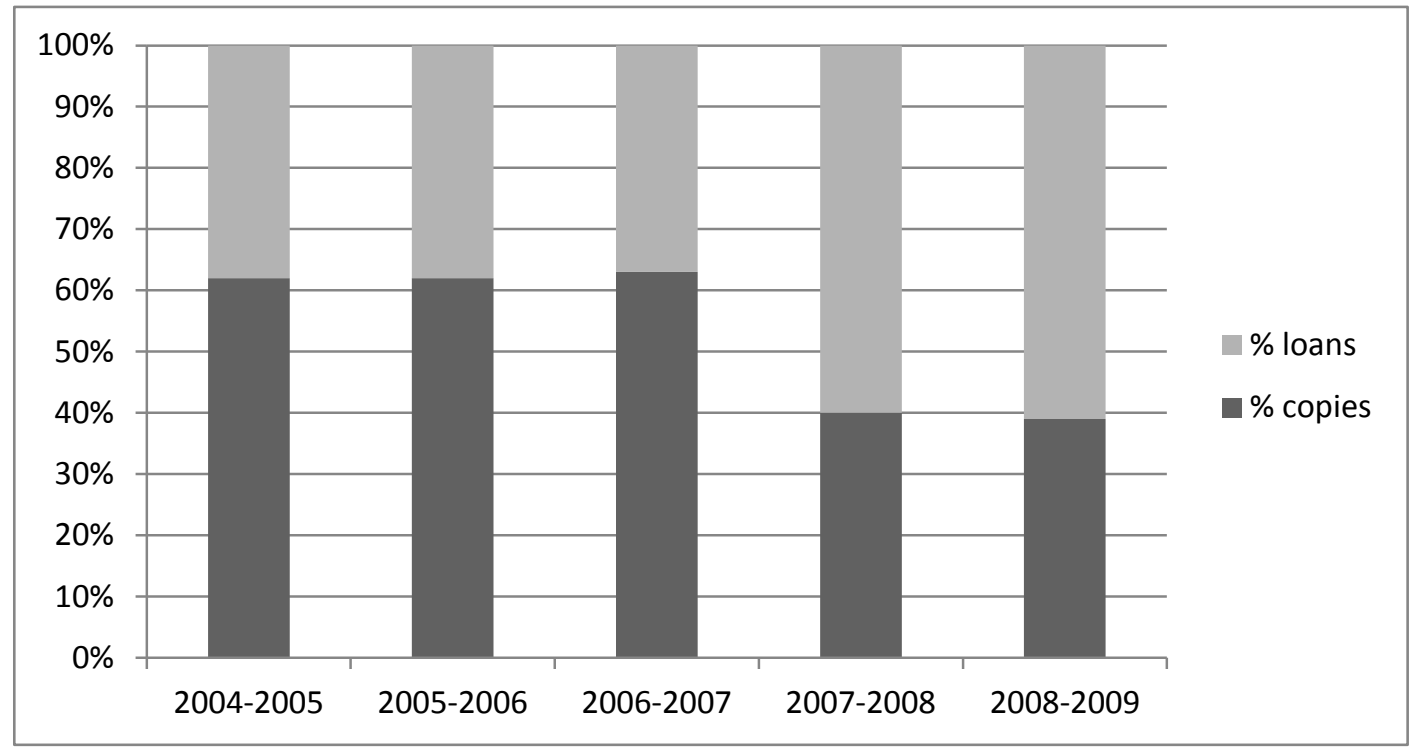

To cope with this increase in workload, 1.0 FTE of additional staff time was added to the office for searching, requesting, and troubleshooting. An additional 1.17 FTE of student hours was 
hired to assist with processing the incoming materials. Staff also revisited requesting and processing material - eliminating unnecessary steps and consolidating others. We activated direct receipt protocols such as ILLiad's Odyssey feature. We did not expand OCLC's ILL Direct Request automation, as frequently the UW owned an alternate edition of requested material that met the patron's need - sending requests for these materials out through ILL Direct Request would mean borrowing items when we owned a suitable alternate copy that was immediately available for the patron to use.

The average out of pocket cost per transaction did not increase much - only 4\%. However, as the increasing variety of items WCL made visible and requestable meant that staff needed to request items from further and further away, and from whatever library held them - it was often not possible to choose the least expensive lender. Our average IFM cost per transaction increased 4\% from $\$ 14.71$ per item in 2006-2007 to $\$ 15.27$ per item in 2007-2008.

Despite a large increase in the numbers of requests cancelled (128\% increase), the fill rate actually improved by $12.6 \%$. This tells us that even though many more items requested were unavailable on ILL, the number of items we were able to borrow overshadowed that. The most common reasons for unfilled requests were non-circulating, too new, in use, or the patron's needby date could not be met.

Not only were requests increasing, and the kinds of things being requested changing, but the demographics of the requesters changed; we saw a 339\% increase in requests from undergraduate students. This is most likely because undergraduate students, as a rule, were unaware of ILL as a potential resource and not accustomed to using it. WCL essentially "drove the users to our door," presenting ILL as a viable delivery mechanism to students who might otherwise have been unaware of it.

Figure 2 


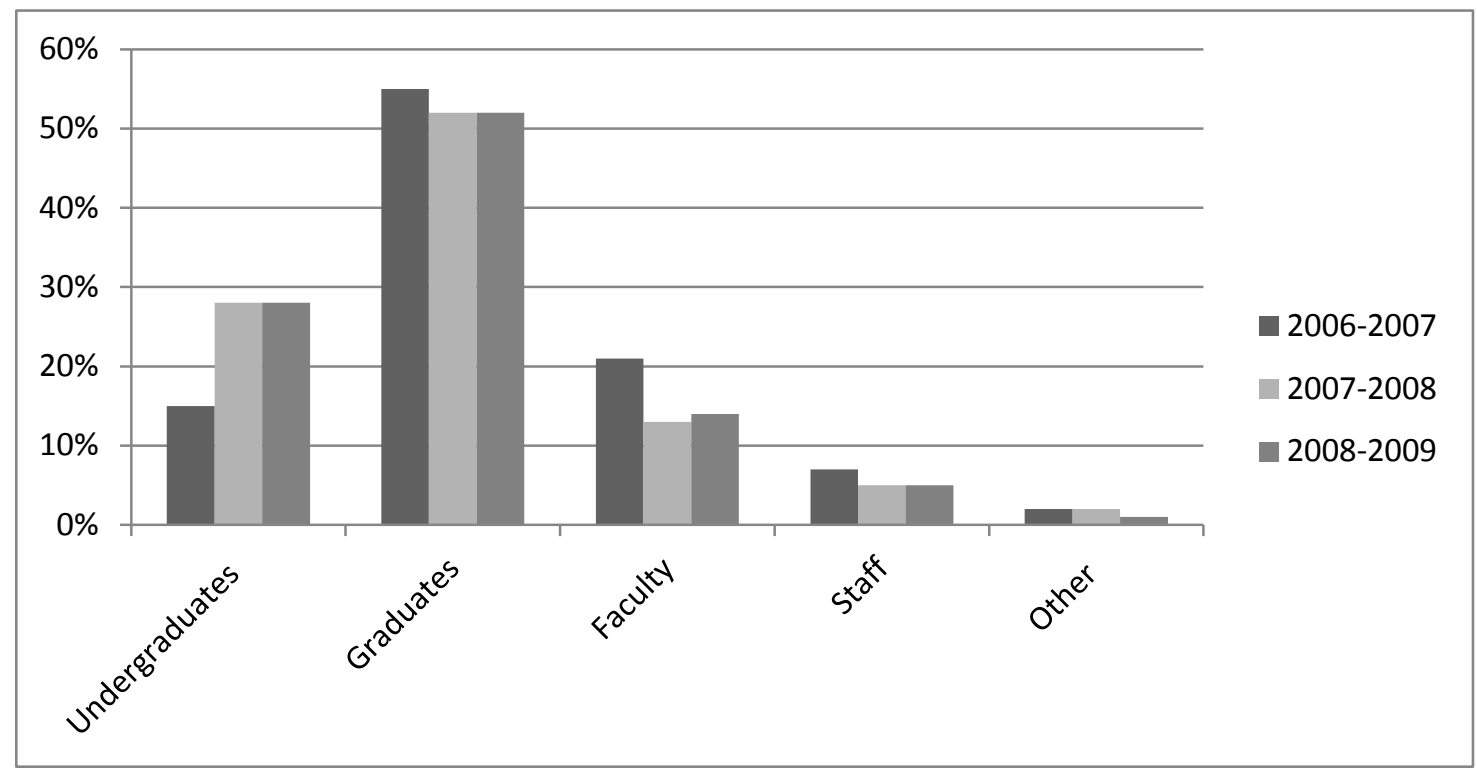

Perhaps in relation to the increase in undergraduate requesting, another interesting trend was the large increase in media items requested through ILL. $21 \%$ of items borrowed were media (VHS, DVD, CD, audio book, etc.). We did not keep historical data on how many media items were requested or received, but anecdotally we can say this is a very significant increase.

Patrons are not charged for ILL requests related to their coursework or UW-related research . However, due in part to the increase in media borrowing, we began enforcing more strictly our "personal use" policy for which we had always charged patrons a fee (\$15, typically); most students honored this agreement and we had very few problem patrons. However, with WCL it is not always obvious what is held locally and what must be requested through ILL, so we saw more requests that we suspected were not research-related. While we wanted to deter this kind of requesting, we did not want to put up barriers to satisfying legitimate research needs. Our compromise was to give patrons five "freebies" - letting five requests for popular and/or media requests go by first, then on the sixth request send a note reminding the patron of our "personal use" policy and inquiring whether the item was for personal use. About one-third responded asking us to cancel the request, another third replied that the item was research-related, and another third did not reply.

Were patrons using the material requested? Inferring from the checkout rate, they were. Only $17 \%$ of items requested were not picked up from the hold shelf. Our circulation staff tell us that approximately $10 \%$ of all items - ILL or non-ILL- on a hold shelf are generally not picked up, and we suspect that the additional $7 \%$ is patrons not wanting to use a Library-Use-Only item. (Many of our very fragile or rare items were restricted to in-library-use only.)

In 2008-2009, year two of WorldCat Local, ILL continued to see activity increase, but at a reduced rate. We acquired 36,443 items (returnables and non-returnables), a 58\% increase in borrowing over the previous year. These requests were filled from 1264 individual 
libraries/article vendors - a 30\% increase in lending libraries. We continued to receive more requests for returnables than for non-returnables; again we suspect this is due to the increased visibility/requestability of returnable material (see Figure 1). We also added another 1.0 FTE of staff and .5 FTE of student hours.

Figure 3

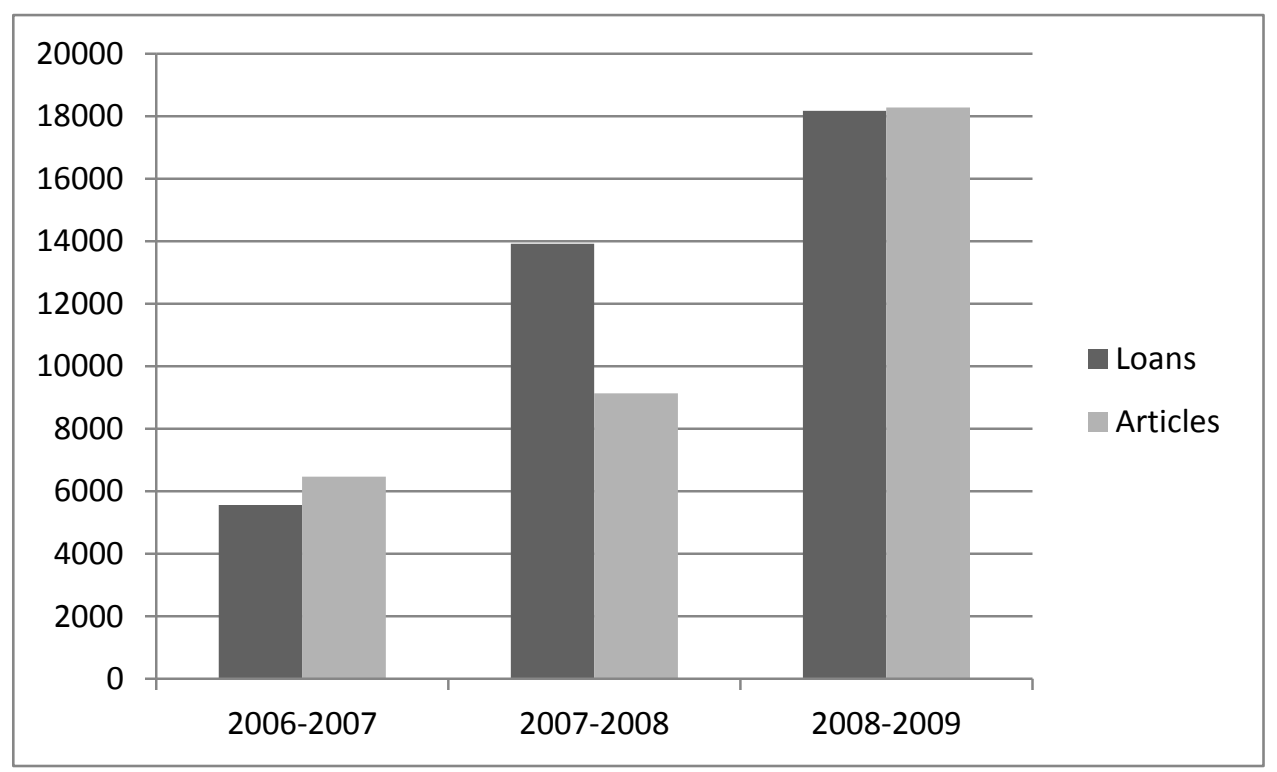

As mentioned earlier the University of Washington actually runs three individual interlibrary loan departments ; in addition to our ILL operations there is also the Health Sciences Interlibrary Loan/Document Delivery Services and the Law Library Interlibrary Loan Department. Some departments charge for ILL, others do not. We found that this non-unified model of ILL services/fees campus-wide was increasingly confusing to patrons. Which request forms did they use? Why did they pay for ILL while some of their colleagues did not? WCL only highlighted this fractured model. It was decided in May 2009 that the Health Sciences and main campus ILL 
operations would be merged to improve customer service and create efficiencies needed to accommodate the increased workload generated by WCL.

The implementation of WCL also increased the number of UW requests to our regional consortia. The consortia, the Orbis Cascade Alliance, maintained the Summit union catalog of the holdings of 35 academic libraries in Washington and Oregon with a total of 29 million items. Prior to WCL a requester accessed Summit materials from within our Innovative catalog by clicking on a Summit search button which would repeat a search in the consortia's INNReach system. Consortial holdings would then be displayed and a request made to deliver the material to the UW. When WCL was implemented all of the Summit holdings were displayed simultaneously with local holdings increasing users' awareness of this material. In the first year (2007-2008) UWL requests for Summit material increased 59\% from 41,000 to 65,000 requests annually. Summit activity had been increasing, but in the 2 years prior to the implementation of WCL the increase had averaged only $16 \%$. To meet the increased Summit workload additional staff and students were hired as the workload increased. During the first year the load-leveling algorithm for the consortia was modified as requests from the UW continually surpassed the number of items supplied by the UW.

\section{WorldCat Local Implementation at Other Libraries}

Other libraries that have implemented WorldCat Local have also seen increases in interlibrary borrowing. There are currently very few libraries as large as the University of Washington Libraries that have implemented WCL early enough to quantify the impacts on interlibrary borrowing. Both Ohio State University Libraries and the University of Delaware Libraries have implemented WCL and have seen increases in activity. Both libraries provide basic ILL for free, have regional consortia and use ILLiad. Ohio State University Libraries (OSUL) implemented WCL as their default search option in February 2008 and then in June 2008 the local catalog was again made the default option. Statistics comparing March 2007 (before WCL) to March 2008 (when WCL was the default) show that book requesting increased more than three times with article requests up about 57\%. Jennifer Kuehn, the ILL librarian at OSUL, reported that, similar to the UWL experience there was a large increase in "non-academic" requests for popular media and other works that were probably not course or research related. OSUL did have automatic processing of requests (OCLC Direct Requesting) functioning during March 2008 which helped them handle the increase. Filed requests for returnables increased $87 \%$. The University of Delaware Libraries (UDL) implemented WCL as its default search option in August 2008. Compared to 2007/2008 UDL saw a 20\% increase in returnables filled with an $8 \%$ overall increase in ILL borrowing activity. All three libraries showed an overall increase in borrowing activity with a lesser increase in article requests. The latter is probably due to WCL's linking of article requests to locally accessible full text databases.

Figure 4 


\begin{tabular}{|l|l|c|c|}
\hline Library & $\begin{array}{l}\text { Time Frame for } \\
\text { Comparison }\end{array}$ & $\begin{array}{l}\text { Increase in Articles } \\
\text { Filled }\end{array}$ & $\begin{array}{l}\text { Increase in } \\
\text { Returnables } \\
\text { Filled }\end{array}$ \\
\hline $\begin{array}{l}\text { University of } \\
\text { Washington Libraries }\end{array}$ & $\begin{array}{l}2006 / 2007- \\
2007 / 2008\end{array}$ & $41 \%$ & $150 \%$ \\
\hline $\begin{array}{l}\text { University of } \\
\text { Washington Libraries }\end{array}$ & $\begin{array}{l}2007 / 2008- \\
2008 / 2009\end{array}$ & $100 \%$ & $31 \%$ \\
\hline $\begin{array}{l}\text { Ohio State University } \\
\text { Libraries }\end{array}$ & $\begin{array}{l}\text { March 2007 - March } \\
2008\end{array}$ & $45 \%$ & $87 \%$ \\
\hline $\begin{array}{l}\text { University of } \\
\text { Delaware Libraries }\end{array}$ & $\begin{array}{l}2007 / 2008- \\
2008 / 2009\end{array}$ & $4 \%$ & $20 \%$ \\
\hline
\end{tabular}

Note: the increase in articles for the University of Washington Libraries in 2008/2009 was due in part to a free scanning service for locally-held print journals. Requests that could not be filled locally were turned into ILL requests increasing the overall request level.

\section{Strategies for Successful Implementation}

The successful implementation of WCL requires that libraries support robust delivery mechanisms and integrate WCL-generated requests with existing library and university services. ILL has been identified in the UWL's strategic planning process as being crucial to supplying users with content identified in WCL. Funding and staff resources have been redirected to ILL to support the new high-volume, high-complexity environment. ILL has also leveraged existing services to provide a more seamless user experience. UWL has utilized the campus-wide net ID system to request WCL - discovered materials through ILL, the consortial system and the local integrated library system (ILS). Once materials are locally received the circulation of ILL and consortial materials are managed through the ILS so that borrowers can check one place for currently checked out materials and receive the same notifications when material is available or becomes overdue. The UWL also has a robust paging system so all local, consortial and ILL materials can be delivered to any library in a matter of hours. Communication and marketing of the service has also been a key element of success as the UWL has worked to mainstream WCL and ILL. Reference staff in particular have been crucial in promoting the service in their dual roles as instructors and departmental liaisons.

\section{Conclusion}

The implementation of WCL with its tight integration of discovery and delivery gives a new primacy to Interlibrary Loan. The University of Washington Libraries has found it challenging to support the new delivery-based model created by WCL. Historically ILL has been an isolated boutique service, hand-crafted for the serious faculty researcher. Requests were made in-person and carefully vetted. Collection development librarians saw every ILL request as a failure of collection development. With the advent of WCL, all library users become aware of an immense universe of content that was previously hidden. With existing free ILL services in place, libraries are seeing requests skyrocket as library users want access to this wealth of content. At 
the University of Washington Libraries ILL filled requests have surpassed the initial circulation statistics of all but the largest library units. Given that circulation in general has decreased, the ILL workload represents a larger and increasing portion of the Libraries public service activity. Related to the increased workload the costs for acquiring ILL materials has gone up - the UWL's IFM costs for ILL increased $82 \%$ from 2006/2007 to 2007/2008 and an additional $36 \%$ during $2008 / 2009$. This shift of workload and expense challenges library administrators to reprioritize services and budgets to support ILL. This requires a significant reallocation of collection development money away from traditional acquisitions to interlibrary loan. ILL-initiated acquisitions should also be considered as part of the fulfillment strategy, especially for materials that maybe frequently requested. Libraries that are planning to implement WCL should plan on a large increase in ILL requests and should prepare to have their ILL operations become a new and important hub of the library service. 